\title{
Polycythemia vera following autologous transplantation for AML: insights on the kinetics of JAK2V617F clonal dominance
}

Elisabetta Antonioli, Paola Guglielmelli, Giada Poli, Valeria Santini, Alberto Bosi and Alessandro M. Vannucchi

Updated information and services can be found at:

http://bloodjournal.hematologylibrary.org/cgi/content/full/110/13/4620

Information about reproducing this article in parts or in its entirety may be found online at:

http://bloodjournal.hematologylibrary.org/misc/rights.dtl\#repub_requests

Information about ordering reprints may be found online at:

http://bloodjournal.hematologylibrary.org/misc/rights.dtl\#reprints

Information about subscriptions and ASH membership may be found online at:

http://bloodjournal.hematologylibrary.org/subscriptions/index.dtl

Blood (print ISSN 0006-4971, online ISSN 1528-0020), is published semimonthly by the American Society of Hematology, $1900 \mathrm{M} \mathrm{St}$, NW, Suite 200, Washington DC 20036.

Copyright 2007 by The American Society of Hematology; all rights reserved.

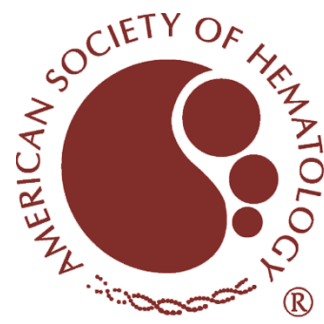


It was estimated at approximately $25 \%$. However, the latter TRM value, along with a relapse rate of $35 \%$, did not result in a significantly superior disease free survival (DFS) in patients beyond 40 years of age with a donor compared with those without a donor.

(2) The commonly used conditioning regimen prior to allogeneic stem cell transplantation (allo-SCT) was high dose cyclophosphamide and myeloablative total body irradiation (TBI; $2 \times 6$ Gy). If patients had received irradiation before, a combination of busulfan and cyclophosphamide was used. The preparative regimen prior to autologous SCT contained highdose busulfan and cyclophosphamide.

(3) Treatment-related mortality data are specifically given in Table 4 of our paper. ${ }^{1}$ Overall, TRM was estimated at $21 \%( \pm 2 \%$, $\mathrm{SD})$ in the donor group and $4 \%( \pm 1 \%)$ in the no-donor group. As most recipients of an allogeneic SCT received TBI, we cannot compare the impact of different transplant techniques.

(4) Anthracyclins used in combination with cytarabin were daunomycin at $45 \mathrm{mg} / \mathrm{m}^{2}$ for 3 days in the first cycle in the HOVON 4/4A studies and idarubicin at $12 \mathrm{mg} / \mathrm{m}^{2}$ for 3 days in the first cycle in the HOVON 29 and 42 studies. In addition, patients treated with chemotherapy as consolidation therapy were treated with mitoxantrone at $10 \mathrm{mg} / \mathrm{m}^{2}$ for 5 days (combined with etoposide; see "Treatment protocols" in Cornelissen et al. ${ }^{1}$ ).

The study by Wiernik et al (cited by Ailawadhi) was performed in patients with acute lymphoblastic leukemia. That same cooperative group has also performed a study in AML, comparing $30 \mathrm{mg} / \mathrm{m}^{2}$ and $45 \mathrm{mg} / \mathrm{m}^{2}$ daunomycin in remission induction. While a higher response rate was observed, no enhanced survival could be demonstrated nor was excessive toxicity noted following the higher dose level of daunomycin $\left(45 \mathrm{mg} / \mathrm{m}^{2}\right){ }^{2}$

(5) Fifty-five patients in the donor group did not proceed to allo-SCT. They were, however, analyzed within the donor group according to the "intention to treat" principle. Reasons for withdrawal from allo-SCT were as follows: refusal $(\mathrm{n}=12)$, worsened condition $(n=9)$, early relapse or death $(n=19)$, good risk cytogenetics $(n=10)$, and unknown causes $(n=5)$. Thus, only a minority of these patients did not proceed to allo-SCT because of favorable risk AML.

(6) As stated in the discussion of our manuscript, data with respect to FLT3 and NMP1 mutations were not available for the majority of patients. As a result, those subsets of patients could not be studied.

We present this letter on behalf of all co-authors.

Jan J. Cornelissen, Wim van Putten, and Bob Löwenberg

Conflict-of-interest disclosure: The authors declare no competing financial interests.

Correspondence: Jan J. Cornelissen, Erasmus University Medical CenterDaniel den Hoed, Department of Hematology, Groene Hilledijk 301, 3075 EA Rotterdam, The Netherlands; e-mail: j.cornelissen@erasmusmc.nl.

\section{References}

1. Cornelissen JJ, Van Putten W, Verdonck LF, et al. Result of a HOVON/SAKK donor versus no-donor analysis of myeloablative HLA-identical sibling stem cell transplantation in first remission acute myeloid leukemia in youngs and middleaged adults: benefits for whom? Blood. 2007;109:3658-3666.

2. Yates J, Clidewell O, Wiernik $P$, et al. Cytosine arabinoside with daunomycin or adriamycin for therapy of acute myelocytic leukemia: a CALGB study. Blood. 1982;60:454-463.

\section{To the editor:}

\section{Polycythemia vera following autologous transplantation for AML: insights on the kinetics of JAK2V617F clonal dominance}

A JAK2V617F mutation is harbored by most patients with polycythemia vera (PV) and has pathogenetic ${ }^{1}$ and diagnostic ${ }^{2}$ relevance. We used this molecular marker to trace origin of disease in a case of PV manifested 5 years after autologous transplantation for acute myeloid leukemia (AML).

A 60-year-old man was diagnosed as having AML, M2 FAB subtype with normal karyotype, in January 1999. Complete remission was obtained after induction chemotherapy with fludarabine, cytarabine, and idarubicin, followed by consolidation with idarubicin and etoposide. He was conditioned with oral busulphan and cyclophosphamide and reinfused with $4.3 \times 10^{6} / \mathrm{kg}$ peripheral blood (PB)-primed C34+ cells in December 1999. Clinical and hematologic follow-up, and bone marrow (BM) biopsies performed yearly thereafter, were unremarkable until March 2006, when he reported pruritus after hot showers, visual disturbance, and paresthesia of a few months' duration. Spleen was palpable, white blood cell count $(\mathrm{WBC})$ was $6.1 \times 10^{9} / \mathrm{L} ; \mathrm{Hb}, 187 \mathrm{~g} / \mathrm{L}(18.7$ $\mathrm{g} / \mathrm{dL}$ ); platelet count, $517 \times 10^{9} / \mathrm{L}$; LDH, $558 \mathrm{U} / \mathrm{L}$; serum ferritin, $10 \mathrm{ng} / \mathrm{mL}$; and erythropoietin $7.6 \mathrm{U} / \mathrm{L}$; endogenous erythroid colonies were present, and karyotype was normal. BM biopsy showed increased cellularity with panmyelosis, prominent erythroid, and megakaryocytic proliferation; JAK2V617F mutation was found, ${ }^{3}$ and diagnosis of PV was established.
Archived BM or PB samples were analyzed for V617F mutation with quantitative polymerase chain reaction (PCR; sensitivity, $<1 \%$; interassay, $\leq 3 \%$ ). ${ }^{4}$ Leukemic blasts at diagnosis, BM cells at remission, and leukapheresis were all V617F negative. A $20 \%$ V617F allele burden was first detected in BM aspirate 4 years after transplantation and it was 25\% 1 year later (May 2005); ad hoc revision of both biopsies failed to satisfy criteria for PV. ${ }^{5}$ At diagnosis, granulocyte V617F allele burden was 28\% (Figure 1).

Although the patient's JAK2 genotype before AML was unknown, normal hematologic parameters 1 year before would exclude a V617Fnegative AML transformed from preexisting, unrecognized, V617Fpositive PV. ${ }^{6}$ A JAK2V617F-positive essen-tial thrombocythemia after transplantation for AML has also been reported. ${ }^{7}$

Availability of sequential samples after AML diagnosis allowed us to trace emergence of mutant clone and to correlate it with disease manifestation. In this patient, the target cell for JAK2V617F mutation was most likely a reinfused hematopoietic stem cell (HSC) that had been exposed to chemotherapy for AML. The time interval between transplantation and appearance of V617F allele was 4 years; of note, this interval is similar to that in a case of PV that developed after chemotherapy for Hodgkin disease ${ }^{8}$ and significantly shorter than the 10 to 20 years reported in nuclear explosion exposure. ${ }^{9}$ Stochastic calculation of the kinetics of clonal 

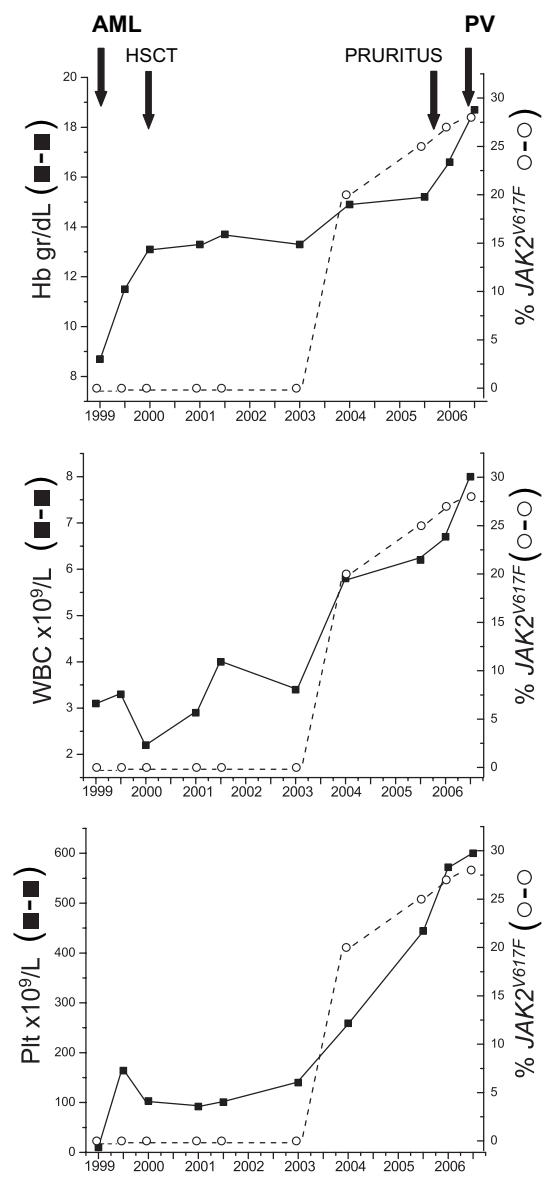

Figure 1. The progressive changes of hematologic parameters (hemoglobin [Hb], white blood cell count [WBC], and platelet count [PLT]; on the left y-axis) and of JAK2V617F allele burden (percent value; on the right y-axis) in samples collected at different times after AML diagnosis. Clinically relevant events (diagnosis of AML or PV, autologous hematopoietic stem-cell transplantation [HSCT], and onset of pruritus) are marked by arrows on the top of the figure.

dominance in animals determined that if the number of neoplastic HSCs reaches $0.5 \%$ of total HSCs, survival and expansion of the clone are assured. ${ }^{10}$ In this particular case, expansion and dominance of a putative V617F mutant cell might have been facilitated by the relatively low total number of HSCs after transplantation, and therefore cannot be considered to reproduce clonal evolution kinetics under usual circumstances. On the other hand, we observed that there was only a 2-year lag phase between first detection of mutant cells and manifestation of PV phenotype.

Therefore, although we cannot generalize from a single observation, this case supports the idea that expansion of JAK2V617F mutant clone in PV is strictly linked with appearance of diseaseassociated abnormalities.

Elisabetta Antonioli, Paola Guglielmelli, Giada Poli, Valeria Santini,
Alberto Bosi, and Alessandro M. Vannucchi

Contribution: E.A. and P.G. contributed to molecular analysis, and collaborated in writing the paper; G.P. contributed to molecular analysis; V.S. collected clinical data; A.B. contributed to paper writing; A.M.V. designed research and wrote the paper.

Conflict-of-interest disclosure: The authors declare no competing financial interests.

Correspondence: Alessandro M. Vannucchi, Department of Hematology, University of Florence, 50134 Florence, Italy; e-mail: amvannucchi@unifi.it.

\section{References}

1. Kaushansky K. On the molecular origins of the chronic myeloproliferative disorders: it all makes sense. Blood. 2005;105:4187-4190.

2. Tefferi A, Thiele J, Orazi A, et al. Proposals and rationale for revision of the World Health Organization diagnostic criteria for polycythemia vera, essential thrombocythemia, and primary myelofibrosis: recommendations from an ad hoc international expert panel. Blood. 2007;110:1092-1097.

3. Baxter EJ, Scott LM, Campbell PJ, et al. Acquired mutation of the tyrosine kinase JAK2 in human myeloproliferative disorders. Lancet. 2005;365:1054-1061.

4. Vannucchi AM, Antonioli E, Guglielmelli P, et al. Prospective identification of high-risk polycythemia vera patients based on JAK2(V617F) allele burden. Leukemia. 2007;21:1952-1959.

5. Tefferi A, Vardiman JW. The diagnostic interface between histology and molecular tests in myeloproliferative disorders. Curr Opin Hematol. 2007;14:115-122.

6. Theocharides A, Boissinot M, Girodon F, et al. Leukemic blasts in transformed JAK2-V617F-positive myeloproliferative disorders are frequently negative for the JAK2-V617F mutation. Blood. 2007;110:375-379.

7. Walker AR, Rothberg PG, Liesveld JL. A case of JAK2 positive essential thrombocythemia 16.5 years after autologous marrow transplantation for AML. Bone Marrow Transplant. 2007;39:725-726.

8. Quirk P, Weinerman BH. Polycythemia vera after chemotherapy-induced remission of Hodgkin's disease: report of a case. Can Med Assoc J. 1980;122: 1399-1400.

9. Hoffman R, Baker KR, Prchal JT. The polycythemias. In: Hoffman R, Benz EJ, Shattil S, Furie B, Cohen HJ, Silberstein LE, McGlave P, eds. Hematology: Basic Principles and Practice. 4th ed. Philadelphia, PA: Elsevier Churcill Livingstone; 2005:1209-1246.

10. Catlin SN, Guttorp P, Abkowitz JL. The kinetics of clonal dominance in myeloproliferative disorders. Blood. 2005;106:2688-2692.

\section{To the editor:}

\section{Development of original donor cell leukemia after successful engraftment from a second donor}

We read with interest the recent review in Blood on donor cell leukemia (DCL) by Flynn and Kaufman. ${ }^{1}$ We report a case of DCL occurring in cells from a first allogeneic stem-cell donor after the patient received a successful transplant from a second donor, following loss of the first donor graft.

The patient, a 32-year-old man, presented with severe aplastic anemia in 1995. No precipitating cause of aplasia was identified. Cytogenetic analysis, Ham test, diepoxybutane breakage analysis, telomerase reverse transcriptase, and RNA component of telomerase mutation screening were normal. Treatment with antilympho- cyte globulin (ALG) and cyclosporin-A initially failed, but subsequent treatment with ALG and oxymethodone led to a 3-year period of transfusion independence. Following disease recurrence with life-threatening cytopenias, after informed consent and ethical approval were obtained in accordance with the Declaration of Helsinki, he received a reduced-intensity conditioning (RIC) peripheral blood stem-cell transplant in June 1999 using fludarabine and cyclophosphamide ${ }^{2}$ and in vivo T-cell depletion with alemtuzumab. The donor was his human leukocyte antigen (HLA)matched mother (donor 1), who was a low-resolution DRB1, 